\title{
Mating-induced reduction in accessory reproductive organ size in the stalk-eyed fly Cyrtodiopsis dalmanni
}

\author{
David W Rogers ${ }^{1}$, Tracey Chapman ${ }^{1}$, Kevin Fowler ${ }^{1}$ and \\ Andrew Pomiankowski*1,2
}

\author{
Address: ${ }^{1}$ The Galton Laboratory, Department of Biology, University College London, 4 Stephenson Way, London NW1 2HE, UK and ${ }^{2}$ Collegium \\ Budapest, Szentháromság utca 2, H-1014 Budapest, Hungary \\ Email: David W Rogers - d.rogers@ucl.ac.uk; Tracey Chapman - t.chapman@ucl.ac.uk; Kevin Fowler - k.fowler@ucl.ac.uk; \\ Andrew Pomiankowski* - ucbhpom@ucl.ac.uk \\ * Corresponding author
}

Published: 09 June 2005

BMC Evolutionary Biology 2005, 5:37 doi:10.1/86/147|-2|48-5-37

This article is available from: http://www.biomedcentral.com/147I-2/48/5/37

(c) 2005 Rogers et al; licensee BioMed Central Ltd.

This is an Open Access article distributed under the terms of the Creative Commons Attribution License (http://creativecommons.org/licenses/by/2.0), which permits unrestricted use, distribution, and reproduction in any medium, provided the original work is properly cited.
Received: 24 February 2005

Accepted: 09 June 2005

\begin{abstract}
Background: Internal reproductive organ size is an important determinant of male reproductive success. While the response of testis length to variation in the intensity of sperm competition is well documented across many taxa, few studies address the importance of testis size in determining other components of male reproductive success (such as mating frequency) or the significance of size variation in accessory reproductive organs. Accessory gland length, but not testis length, is both phenotypically and genetically correlated with male mating frequency in the stalk-eyed fly Cyrtodiopsis dalmanni. Here we directly manipulate male mating status to investigate the effect of copulation on the size of both the testes and the accessory glands of $C$. dalmanni.
\end{abstract}

Results: Accessory gland length was positively correlated with male mating frequency. Copulation induced a significant decrease in accessory gland size. The size of the accessory glands then recovered slowly over the next 8-48 hours. Neither testis length nor testis area was altered by copulation.

Conclusion: These results reveal that the time course of accessory gland recovery corresponds to field observations of mating behaviour and suggest that accessory gland size may limit male mating frequency in $C$. dalmanni.

\section{Background}

There is a considerable body of evidence that reproductive organ size contributes to male reproductive success. This mainly derives from interspecific comparisons that have found positive relationships between testis size and the risk of sperm competition [1-5]. In addition, the direct manipulation of sperm competition intensity under experimental evolution has been shown to cause correlated changes in testes size in two species of Diptera [6,7].
However, few studies have addressed the importance of internal reproductive organ size to other components of male reproductive success, or the significance of size variation in accessory reproductive organs which are often vital for sperm transfer, fertility, and essential for success in sperm competition $[8,9]$.

In this paper, we investigate how reproductive organ size may limit male mating frequency under conditions where 
males encounter high numbers of mating opportunities and are thus potentially at risk of sperm or seminal fluid depletion [10-12]. Previous data support the hypothesis that male mating frequency can be limited by reproductive organ size in insects. For example, in dung flies, the length of the proximal section of the testis decreases with the number of copulations achieved in Scathophaga stercoraria [13] and increasing copula duration in Sepsis cynipsea [14]. Testis mass is also lower in mated than in unmated Dawson's burrowing bees Amegilla dawsoni [15]. In contrast, accessory gland size, but not testis size, is phenotypically correlated with male mating frequency in Drosophila melanogaster [16] and accessory glands become completely depleted and reduced in volume after 4-5 matings, leading to decreased fertility even though motile sperm remain in the seminal vesicles $[17,18]$. The ability to replenish reserves of sperm and seminal fluid likely further constrains male mating frequency (reviewed in [10]). Mating stimulates the replenishment of accessory gland products in D. melanogaster [19]. This resynthesis reaches a maximum after 2-4 hours and decreases to basal levels after 48 hours in Drosophila funebris [20].

In this study, we used the stalk-eyed fly Cyrtodiopsis dalmanni to test whether testis and accessory gland size are affected by mating. This is an ideal species, as males and females regularly mate at extremely high frequency [2123 ]. Over $90 \%$ of matings occur in nocturnal aggregations which usually consist of a single male and a harem of several females [24] (up to 24 in the closely related species Cyrtodiopsis whitei [25]). Females join aggregations each evening and mate in the period immediately following dawn before dispersing $[25,26]$. During copulation, males transfer a single small spermatophore composed of sperm from the testes enveloped in accessory gland secretions [27]. Previous work has shown that accessory gland length, but not testis length, is phenotypically correlated with male mating frequency [22]. Additionally, bidirectional artificial selection on male mating frequency resulted in a correlated response in accessory gland length but not in testis length [23]. While correlative evidence, whether phenotypic or genetic, indicates an association between accessory gland size and male mating frequency, it does not establish a direct physiological relationship between these two variables. In the current study, we provide direct evidence that mating induces a decrease in accessory gland, but not testis, size. Furthermore, we demonstrate that the timecourse of post-copulatory recovery of accessory gland size closely mirrors field observations of mating patterns in C. dalmanni.

\section{Results}

We manipulated male mating status by providing males with the opportunity to mate with 6 virgin females for 60 minutes immediately following artificial dawn. Mated males were dissected at fixed times following this mating period ( 0 hours, 2 hours, 8 hours, 24 hours and 48 hours) and the sizes of their testes and accessory glands were compared to unmated control males. Mating resulted in a significant decrease in accessory gland length, but glands returned to their original size over the course of the next 8 to 48 hours. At average levels of male eyespan, included to as a measure of body size to control for allometric variation $\left(F_{1,185}=5.25, p=0.0231\right)$, mating status affected accessory gland length $\left(F_{5,185}=4.72, p=0.0004\right)$. Post-hoc Tukey HSD tests revealed that males dissected immediately after mating or 2 hours after mating exhibited significantly smaller accessory glands than unmated controls. Gland length began to recover after 8 hours and by 48 hours after mating the accessory glands were significantly longer than immediately following mating (Fig. 1). Removing unmated control males from the analysis revealed a positive effect of mating frequency on accessory gland length $\left(b \pm\right.$ s.e. $=0.0228 \pm 0.0086, t_{149}=2.67, p=$ $0.0085)$ after controlling for the significant effect of recovery time $\left(F_{4,149}=3.38, p=0.0111\right)$. Males mated a mean \pm s.e. of $3.79 \pm 0.20$ (range: $1-12$ ) times during the course of the 60 minute observation period, and mating frequency did not vary between groups dissected at different times $\left.F_{4,150}=1.08, p=0.3667\right)$. Identical results were obtained when accessory gland length was replaced with area, but are not included as accessory gland length and the square root of area were highly positively correlated $\left(\mathrm{r}_{90}=0.926, p<0.0001\right)$.

Mating did not result in a decrease in testis length compared to unmated controls (Tukey HSD, Fig. 2). However, significant differences in testis length were detected between males measured at different recovery times $\left(F_{5,185}=3.10, p=0.0102\right)$. Post-hoc Tukey HSD tests revealed that males allowed to recover for 48 hours exhibited shorter testes than males allowed to recover for 2 or 24 hours. Testis length scaled with male eyespan $\left(F_{1,185}=\right.$ $1.71, p=0.0054)$. Removing unmated males from the analysis failed to reveal any association between testis length and mating frequency $\left(F_{1,147}=0.68, p=0.4100\right)$ after controlling for recovery time $F_{4,147}=3.66, p=$ $0.0071)$ and eyespan $\left(F_{1,147}=4.33, p=0.0392\right)$. Testis length and the square root of area were positively correlated $\left(\mathrm{r}_{61}=0.691, p<0.0001\right)$. As testis length explained less than half of the variance in testis area $\left(r^{2}=0.477\right)$, we also directly compared testis area in males immediately after mating to that in unmated controls and detected no difference $($ mean \pm s.e.: mated $=0.801 \pm 0.021$, unmated $\left.=0.792 \pm 0.020, t_{65}=0.276, p=0.7834\right)$.

\section{Discussion}

Male accessory gland size in C. dalmanni decreased dramatically following copulation and slowly recovered over the next 8-48 hours. After removing the effect of recovery 


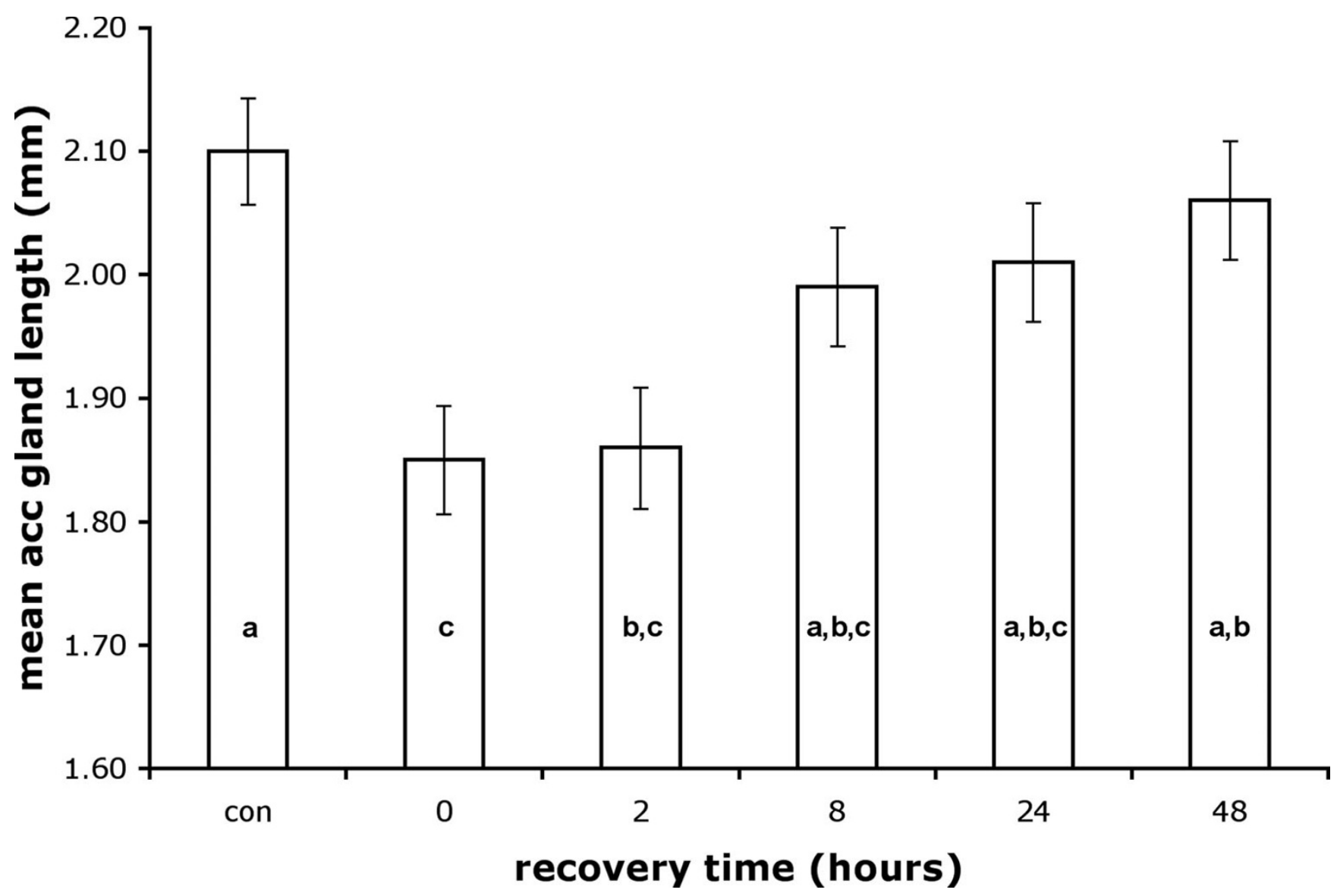

Figure I

Reduction and subsequent recovery of accessory gland length following mating. Mean accessory gland length decreased from $2.10 \mathrm{~mm}$ to $1.85 \mathrm{~mm}$ following mating and was restored to the original size within 8-48 hours. Controls (con) were unmated (virgin) males. Columns not marked with the same letter are significantly different (Tukey HSD). Values shown are least squares means \pm s.e. at average values of male eyespan.

time, accessory gland length was positively correlated with male mating frequency. Neither testis length nor testis area appeared to be altered by copulation; no significant difference in testis length was observed between mated and unmated males in the 48 hours following copulation.

Both male and female stalk-eyed flies mate frequently. In the current study, each male mated an average of 3.79 times (up to a maximum of 12) during the 60-minute observation period. Only $23.9 \%$ (37 out of 155) of males mated at least 6 times and therefore $76.1 \%$ (118 out of 155 ) of males failed to mate with all 6 virgin females provided. As females housed with three males will mate an average of 5.51 times during the 60 minutes following artificial dawn [28], it is clear that male mating frequency was limited by physiological ability rather than the availability of willing females.
In the field, copulations occur primarily at dawn $[24,25]$. Our observations of the recovery of the accessory glands match this behavioural pattern, as 24 hours after copulation (i.e. the subsequent dawn period), the accessory glands had recovered their original pre-mating size. We found that the accessory glands had partially recovered after 8 hours which is consistent with the lower frequency of mating observed at dusk $[24,25]$, whereas little recovery was observed in the hours immediately following copulation when flies leave mating aggregations to forage.

The two most plausible physiological constraints on male mating frequency in C. dalmanni are the availability of accessory gland products and the availability of sperm, both of which are required to produce spermatophores [27]. Several lines of evidence indicate that accessory gland size is more likely to limit mating frequency than 


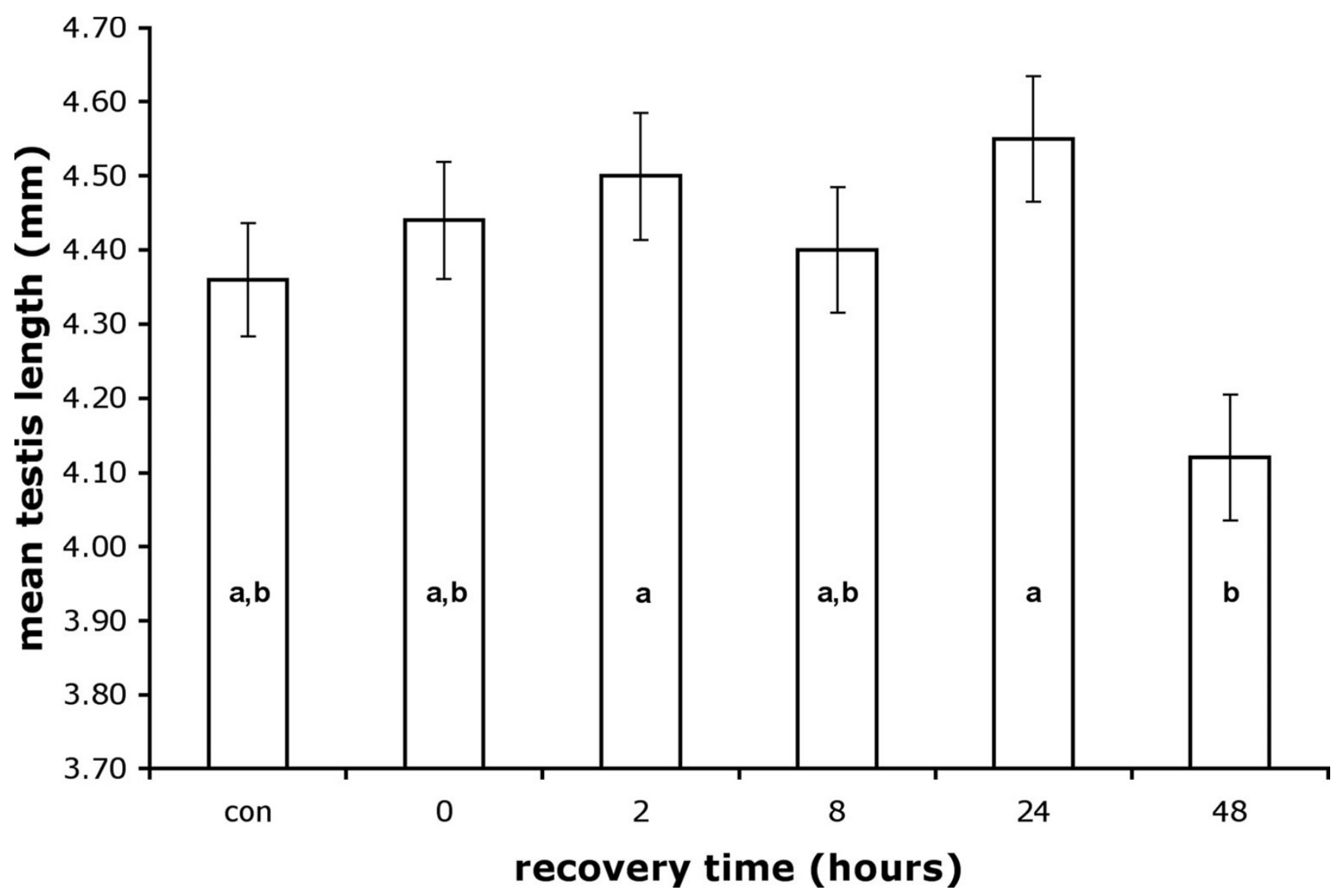

Figure 2

Response of testis length to mating. Males dissected 48 hours after mating exhibited smaller testes than males dissected at 2 hours and 24 hours post-mating. Controls (con) were unmated (virgin) males. Columns not marked with the same letter are significantly different (Tukey HSD). Values shown are least squares means \pm s.e. at average values of male eyespan.

testis length. First, we have demonstrated a decrease in accessory gland size following copulation and the subsequent recovery closely mirrors mating behaviour in the field. No significant reduction in testis size was observed in mated males compared to unmated controls. Second, our study confirms the results of a previous experiment showing that accessory gland length, but not testis length, is phenotypically correlated with male mating frequency [22]. Third, bidirectional artificial selection on male mating frequency produced a correlated response in accessory gland length but not testis length [23]. However, we cannot exclude the possibility that some other currently unknown factor is the primary constraint on male mating frequency in C. dalmanni.

The full importance of the accessory glands in stalk-eyed fly reproduction is poorly understood. Accessory gland products form the casing of the spermatophore and con- sequently are necessary for sperm transfer [27]. Furthermore, accessory gland products appear to be important in sperm competition as seminal fluid can decrease the viability of sperm from particular rival males in the female spermathecae [29]. However, in contrast to D. melanogaster [30], accessory gland products do not appear to play a role in sperm displacement [29], the inhibition of female remating [31] or the manipulation of female fecundity [28]. Consequently, the advantage of large accessory glands is likely gained through both increased mating frequency (by allowing males to produce more spermatophores over a given time period) and, potentially, greater success under sperm competition.

\section{Conclusion}

When receptive females are not limiting, male mating frequency in C. dalmanni is likely constrained by accessory gland size. Copulation causes a significant reduction in 
accessory gland size and replenishment of the depleted accessory glands follows a time course that is consistent with the observed daily peak in male mating frequency at dawn. There was no reduction in testis size following mating and therefore testis size appears to be of less importance in determining male mating frequency in this species.

\section{Methods}

\section{General methods}

The base stock was an outbred laboratory population of the stalk-eyed fly, C. dalmanni, collected from Gombak, Malaysia in 1993. The stock was maintained in large cages at high population size (typically more than 200 individuals per cage) and with a 1:1 sex ratio. Flies were fed ground corn medium and kept at $25^{\circ} \mathrm{C}$ on a $12 \mathrm{~h} / 12 \mathrm{~h}$ light/dark regime. The regime included a 15-min "dawn" period in which the culture room was illuminated by a single $60-\mathrm{W}$ bulb. All observations of behaviour commenced at the start of this dawn period.

\section{Manipulation of male mating status}

Experimental flies were raised from eggs collected in groups of 13 from the population cages and allowed to hatch on moist cotton pads in Petri dishes containing at least $2 \mathrm{~g}$ of ground corn (maize). Upon eclosion, flies were segregated according to sex and raised to sexual maturity in groups of 10 housed in $1.5 \mathrm{~L}$ plastic pots on an ad libitum diet of ground corn. Mating observations were conducted using virgin males aged 6 weeks post-eclosion and virgin females aged 6-8 weeks post-eclosion. Males were randomly assigned to 5 mating status groups: unmated controls $(\mathrm{n}=36), 0$ hours recovery $(\mathrm{n}=38), 2$ hours recovery $(n=29), 8$ hours recovery $(n=30), 24$ hours recovery $(\mathrm{n}=30)$, and 48 hours recovery $(\mathrm{n}=30)$. At artificial dawn, individual males were added to $1.5 \mathrm{~L}$ plastic pots containing 6 females, except for control males which were placed in empty $1.5 \mathrm{~L}$ pots. The number of copulations over 40 seconds in duration occurring during the subsequent 60 -minute period was recorded. Males that failed to mate during this observation period were discarded. Unmated control males and 0 hour recovery males were immediately placed on ice and dissected. Males assigned to other recovery periods were moved individually to $500 \mathrm{ml}$ plastic pots lined with a moist cotton pad and provided with ground corn until the appropriate time of dissection.

\section{Morphological measurements}

Males were dissected in a small amount of phosphate buffered saline on a microscope slide. Images of the accessory glands and uncoiled testes were captured using a monocular microscope connected via a video camera to a Macintosh computer with NIH Image (version 1.55). Length was measured by tracing a midline that longitudi- nally bisected each organ and the mean length of the two accessory glands or testes was used in analyses. Area was measured by tracing the outline of each organ and calculating the longitudinal surface area. Areas of both accessory glands were calculated and the mean used in analyses, but a single randomly chosen testis was measured per individual. Eyespan, was defined as the distance between the outer tips of the eyes.

\section{Statistical analyses}

Unless otherwise indicated, general linear models were used to analyse the determinants of reproductive organ size. Initial models included an intercept, male eyespan, recovery time and the eyespan $\times$ recovery time interaction. Recovery time was coded into models as an ordinal categorical variable. Stepwise elimination was used to remove terms that failed to significantly improve the fit of the model. Secondary analyses extended the models to include the number of copulations observed which required the exclusion of control males that did not copulate. Data sets did not deviate significantly from the assumptions of general linear modelling.

\section{Authors' contributions}

DWR conceived of the study, contributed to the design, carried out the experimental work and statistical analysis, and drafted the manuscript. TC, KF, and AP participated in the design and coordination of the study and helped to draft the manuscript. All authors read and approved the final manuscript.

\section{Acknowledgements}

The authors thank Matthew Denniff for assistance with fly rearing and behavioural observations, and two anonymous referees for their helpful comments on the manuscript. This research was funded by awards from the Natural Environment Research Council (TC, KF \& AP), the Royal Society (TC) and the Association of Commonwealth Universities (DWR).

\section{References}

I. Harcourt AH, Harvey PH, Larson SG, Short RV: Testis weight, body weight and breeding system in primates. Nature 1981, 293:55-57.

2. Møller AP: Sperm competition, sperm depletion, paternal care, and relative testis size in birds. Am Nat 1991, 137:882-906.

3. Gage MJG: Association between body size, mating pattern, testis size and sperm lengths across butterflies. Proc $R$ Soc Lond B 1994, 258:247-254.

4. Hosken DJ: Sperm competition in bats. Proc R Soc Lond B 1997, 264:385-392.

5. Stockley P, Gage MJG, Parker GA, Møller AP: Sperm Competition in fishes: the evolution of testis size and ejaculate characteristics. Am Nat 1997, 149:933-954.

6. Pitnick S, Miller GT, Regan J, Holland B: Males' evolutionary responses to experimental removal of sexual selection. Proc $R$ Soc Lond B 200I, 268: 107|-1080.

7. Hosken DJ, Ward PI: Experimental evidence for testis size evolution via sperm competition. Ecol Lett 200I, 4:10-13.

8. Leopold RA: The role of male accessory glands in insect reproduction. Annu Rev Entomol 1976, 2 I:199-221. 
9. Gillot C: Male accessory gland secretions: modulators of female reproductive physiology and behavior. Annu Rev Entomol 2003, 48: 163-184.

10. Dewsbury DA: Ejaculate cost and male choice. Am Nat 1982 , I 19:60I-6I0.

II. Cartar RV: Testis size in sandpipers. Naturwissenschaften 1985 72:157-I58.

12. Preston BT, Stevenson IR, Pemberton JM, Wilson K: Dominant rams lose out by sperm depletion. Nature 200I, 409:68I-682.

13. Ward PI, Simmons LW: Copula duration and testes size in the yellow dung fly, Scathophaga stercoraria (L.): the effects of diet, body size, and mating history. Behav Ecol Sociobiol |99|, 29:77-85.

14. Martin OY, Hosken DJ: Strategic ejaculation in the common dung fly Sepsis cynipsea. Anim Behav 2002, 63:54I-546.

15. Simmons LW, Tomkins JL, Alcock J: Can minor males of Dawson's burrowing bee, Amegilla dawsoni (Hymenoptera: Anthophorini) compensate for reduced access to virgin females through sperm competition? Behav Ecol 2000, I I:319-325.

16. Bangham J, Chapman T, Partridge L: Effects of body size, accessory gland and testis size on pre- and postcopulatory success in Drosophila melanogaster. Anim Behav 2002, 64:915-921.

17. Lefevre G, Jonsson UB: Sperm transfer, storage, displacement, and utilization in Drosophila melanogaster. Genetics 1963, 47:1719-1736.

18. Hihara F: Effects of the male accessory gland secretion on oviposition and remating in females of Drosophila melanogaster. Zool Mag 1981, 90:307-316.

19. Herndon LA, Chapman T, Kalb JM, Lewin S, Partridge L, Wolfner MF: Mating and hormonal triggers regulate accessory gland gene expression in male Drosophila. J Insect Physiol 1997, I 2: | | 17-II 23.

20. Baumann $\mathrm{H}$ : The isolation, partial characterization, and biosynthesis of the paragonial substances, PS-I and PS-2, of Drosophila funebris. J Insect Physiol 1974, 20:2 I8I-2194.

21. Baker RH, Ashwell RIS, Richards TA, Fowler K, Chapman T, Pomiankowski $A$ : Effects of multiple mating and male eye span on female reproductive output in the stalk-eyed fly Cyrtodiopsis dalmanni. Behav Ecol 200I, I 2:732-739.

22. Baker RH, Denniff M, Futerman P, Fowler K, Pomiankowski A, Chapman $\mathrm{T}$ : Accessory gland size influences time to sexual maturity and mating frequency in the stalk-eyed fly, Cyrtodiopsis dalmanni. Behav Ecol 2003, 14:607-6II.

23. Rogers DW, Baker RH, Chapman T, Denniff M, Pomiankowski A Fowler K: Direct and correlated responses to artificial selection on male mating frequency in the stalk-eyed fly Cyrtodiopsis dalmanni. J Evol Biol 2005, 18:642-650.

24. Wilkinson GS, Reillo PR: Female choice response to artificial selection on an exaggerated male trait in a stalk-eyed fly. Proc R Soc Lond B 1994, 255: I-6.

25. Lorch PD, Wilkinson GS, Reillo PR: Copulation duration and sperm precendence in the stalk-eyed fly Cyrtodiopsis whitei (Diptera: Diopsidae). Behav Ecol Sociobiol 1993, 32:303-3II.

26. Burkhardt $D$, de la Motte I: Physiological, behavioural, and morphometric data elucidate the evolutive significance of stalked eyes in Diopsidae (Diptera). Entomol Gen 1987, 1 2:221-233.

27. Kotrba M: Sperm transfer by spermatophore in Diptera: new results from Diopsidae. Zool J Linn Soc 1996, I I 7:305-323.

28. Reguera P, Pomiankowski A, Fowler K, Chapman T: Low cost of reproduction in female stalk-eyed flies, Cyrtodiopsis dalmanni. J Insect Physiol 2004, 50:103-108.

29. Fry CL, Wilkinson GS: Sperm survival in female stalk-eyed flies depends on seminal fluid and meiotic drive. Evolution 2004 58:1622-1626.

30. Wolfner MF: The gifts that keep on giving: physiological functions and evolutionary dynamics of male seminal proteins in Drosophila. Heredity 2002, 88:85-93.

31. Grant CA, Fowler K, Chapman T: No reduction of female sexual receptivity following mating in a stalk-eyed fly, Cyrtodiopsis dalmanni (Diptera: Diopsidae). J Evol Biol 2002, 15:2 10-2I5.
Publish with Bio Med Central and every scientist can read your work free of charge

"BioMed Central will be the most significant development for disseminating the results of biomedical research in our lifetime. "

Sir Paul Nurse, Cancer Research UK

Your research papers will be:

- available free of charge to the entire biomedical community

- peer reviewed and published immediately upon acceptance

- cited in PubMed and archived on PubMed Central

- yours - you keep the copyright

Submit your manuscript here:

http://www.biomedcentral.com/info/publishing_adv.asp
BioMedcentral 